\title{
Excessive Daytime Sleepiness and Hypertension in Cameroonian Adult Population
}

\author{
Eric Walter Pefura-Yone ${ }^{1,2, *}$, Olen Jean Pierre Kamga ${ }^{1,3}$, Adamou Dodo Balkissou ${ }^{4}$, \\ Jérôme François Kaze-Folefack ${ }^{1,5}$, Amadou Djenabou' ${ }^{6}$, Virginie Poka-Mayap ${ }^{2}$, Alain Kuaban ${ }^{1}$, \\ Haman Djabbo Abdoul Whahab ${ }^{7}$, Sounou Asmaou ${ }^{8}$, Corine Kenne-Kenyo ${ }^{9}$, Christopher Kuaban ${ }^{10}$ \\ ${ }^{1}$ Department of Internal Medicine and Specialties, Faculty of Medicine and Biomedical Sciences, University of Yaoundé 1, Yaoundé, \\ Cameroon \\ ${ }^{2}$ Pneumology A Service, Yaoundé Jamot Hospital, Yaoundé, Cameroon \\ ${ }^{3}$ Psychiatry A Service, Yaoundé Jamot Hospital, Yaoundé, Cameroon \\ ${ }^{4}$ Faculty of Medicine and Biomedical Sciences of Garoua, University of Ngaoundéré, Garoua, Cameroon \\ ${ }^{5}$ Nephrology Center, Yaoundé Teaching Hospital, Yaoundé, Cameroon \\ ${ }^{6}$ HIV Approved Treatment Center, Yaoundé Jamot Hospital, Yaoundé, Cameroon \\ ${ }^{7}$ Sub-division Health Medical Center of Koza, Koza, Cameroon \\ ${ }^{8}$ Meiganga District Hospital, Meignaga, Cameroon \\ ${ }^{9}$ Institut Supérieur de Technologie Médicale, Yaoundé, Cameroon \\ ${ }^{10}$ Faculty of Health Sciences, University of Bamenda, Bamenda, Cameroon
}

\section{Email address:}

Pefura2002@yahoo.fr (E.W. Pefura-Yone), olen_cm@yahoo.fr (O.J. P. Kamga), dodobalkissou@gmail.com (A. D. Balkissou), f_kaze@yahoo.fr (J. F. Kaze-Folefack), djenabouamadou@yahoo.fr (A. Djenabou), pokavirginie@yahoo.fr (V. Poka-Mayap), kuabanallen@yahoo.com (A. Kuaban), abdoulwahhab@gmail.com (H. D. A. Whahab), asmaousounou@gmail.com (S. Asmaou), corinekenyokenne@yahoo.fr (C. Kenne-Kenyo), ckuaban@yahoo.fr (C. Kuaban)

${ }^{*}$ Corresponding author

\section{To cite this article:}

Eric Walter Pefura-yone, Olen Jean Pierre Kamga, Adamou Dodo Balkissou, Jérôme François Kaze-Folefack, Amadou Djenabou, Virginie Poka-Mayap, Alain Kuaban, Haman Djabbo Abdoul Whahab, Sounou Asmaou, Corine Kenne-Kenyo, Christopher Kuaban. Excessive Daytime Sleepiness and Hypertension in Cameroonian Adult Population. American Journal of Internal Medicine.

Vol. 8, No. 1, 2020, pp. 8-13. doi: 10.11648/j.ajim.20200801.12

Received: December 18, 2019; Accepted: December 30, 2019; Published: January 8, 2020

\begin{abstract}
Data on association between excessive daytime sleepiness (EDS) and hypertension are very limited in subSaharan Africa. The aim of this study was to look for an independent association between EDS and hypertension and identify the factors associated to EDS in adult subjects with hypertension in Cameroon. Data from cross-sectional community surveys conducted from 2015 to 2018 in three regions of Cameroon (West, Littoral, and North) were analyzed. The participants aged $\geq$ 19 years were included using multilevel stratified random sampling method. EDS was defined as an Epworth score $\geq 10$. Subjects were considered to have hypertension if they were on treatment for hypertension or had a blood pressure $\geq 140 / 90$ $\mathrm{mmHg}$ measured by standard protocols. Logistic regression was used to investigate the factors associated to EDS. The p-value $<0.05$ was set as significant statistical threshold. A total of 8288 subjects $(55.2 \%$ females $)$ of median age $\left(25^{\text {th }}-75^{\text {th }}\right.$ percentiles $)$ of 39 (27-54) years were included. The prevalence of EDS was higher in subjects who had hypertension as than in those without hypertension $(13.4 \%$ vs $11.5 \%, \mathrm{p}=0.015)$, with an unadjusted odds ratio (IC 95\%) of 1.19 (1.04-1.38). After multivariate analysis including place of residence, age, sex, education level and body mass index (BMI), we did not find an independent association between EDS and hypertension [odds ratio 95\% CI): $1.01(0.8-1.18), p=0.937]$. The determinants of EDS in subjects with hypertension were residence in Bandjoun [2.23 (1.12-4.11), $\mathrm{p}=0.10]$, Douala [2.78 (1.48-5.25), $\mathrm{p}=$ $0.002]$ and Garoua [1.95 (1.01-3.74), $\mathrm{p}=0.045]$ compared to Figuil; and BMI [1.04 (1.02-1.06) per 1 $\mathrm{kg} / \mathrm{m} 2$ increase, $\mathrm{p}=$ 0.001]. In conclusion, we did not find an independent association between EDS and hypertension in Cameroon. Obesity is associated with EDS in subjects with hypertension.
\end{abstract}


Keywords: Sleep Disorders, Daytime Sleepiness, Sleep Apnea Syndrome, High Blood Pressure, Hypertension

\section{Introduction}

Excessive daytime sleepiness (EDS) is a common clinical problem. It is one of the main consequences of sleep disorders and it is associated with a reduction of the quality of life, road accidents and workplace accidents [1,2]. EDS is an inability to maintain vigilance and alertness during major period of the day when subject is expected to be awake, with sleep occurring unintentionally or at inappropriate times and this almost daily [3]. Its prevalence is estimated between 10 and $20 \%$ in the general population [4-12] and reaches $68 \%$ in some groups of patients [13]. The independent association between EDS and hypertension is found in several studies including patients with sleep apnea syndrome (SAS) [13-16]. Hypertension is a common condition in the general population and is one of the major risk factors for cardiovascular mortality and morbidity [17]. Studies of the relationship between EDS and hypertension in the general population regardless of association with SAS are scarce. In a prospective cohort study carried out in a relatively healthy adult population, Goldstein et al. found a high risk of developing hypertension in subjects with EDS [18]. Otherwise, in a recent prospective cohort study in Brazil, Drager et al. did not find any association between hypertension and EDS [19]. Moreover, in a group of subjects recruited from a sleep laboratory in China, normotensive subjects had a more severe SDE than hypertensive subjects with OSA [20]. The factors associated with EDS in hypertensive subjects are obesity, type 2 diabetes and uncontrolled hypertension [21]. In this light, we carried out this study having as objective to investigate the association between the EDS and hypertension, and to determine the factors associated with the EDS in the subjects having hypertension in the general adult population of Cameroon.

\section{Methods}

\subsection{Setting and Participants}

This cross-sectional community based study was carried out from November 2015 to April 2018. Subjects were recruited in the health district of Bandjoun (semi-urban and rural area) of the western region of Cameroon from November 2015 to April 2016, in the city of Douala (urban area, Littoral region) from November 2016 to April 2017 and in the city of Garoua (urban area, North region) and Figuil (semi-urban area, North region) from December 2017 to April 2018. Subjects aged 19 and above who gave their informed consent to participate in the study were included.

\subsection{Sampling}

The sampling method used in this study has been published elsewhere [22]. In summary, multi-level stratified sampling method was applied in each recruitment area. At the first level, the enumeration areas corresponding to those used for the national immunization days were selected by random sampling. At the second level, households were selected by systematic sampling with variable sampling rate according to the size of each enumeration area. Subjects aged at least 19 years living in the households selected at the second level were then invited to participate in these surveys.

\subsection{Data Collection}

The data were collected by the final year medical students. Socio-demographic data including age, sex, level of formal education, marital status and ethnic group were recorded. Smoking habits were identified and subjects classified as: smoker (a subject who reported having smoked at least one cigarette a day for at least one year or who had smoked at least 20 packs of cigarettes in his life and who continues to smoke), ex-smoker (anyone who reported stopping smoking for at least 6 months) and non-smoker. Alcohol consumption was classified as regular consumption, occasional consumption, former consumption, non-consumption [23]. Weight (kg) and height $(\mathrm{m})$ were used to calculate body mass index (BMI) as the ratio of weight $(\mathrm{kg})$ to the square of height $(\mathrm{m})$. The different categories of body mass index (BMI) are those used internationally and include: BMI $<18.5 \mathrm{~kg} / \mathrm{m} 2$ (underweight), BMI of 18.5 to $24.9 \mathrm{~kg} / \mathrm{m} 2$ (normal), BMI of 25 to $29.9 \mathrm{~kg} /$ $\mathrm{m} 2$ (overweight) and BMI $\geq 30 \mathrm{~kg} / \mathrm{m} 2$ (obesity). The history of hypertension and antihypertensive therapy were recorded and the arterial blood pressure measured three times in sitting position $\left(5^{\text {th }}, 10^{\text {th }}\right.$ and $15^{\text {th }}$ minute of rest) according to standard methods [17] using a OMRON electronic sphygmomanometer (OMRON HEALTHCARE, Kyoto, Japan). A subject was considered having hypertension if he was taking antihypertensive drugs for hypertension or if the average arterial blood pressure taken at the $10^{\text {th }}$ and $15^{\text {th }}$ minute of rest was greater than or equal to $140 \mathrm{mmHg}$ for systolic and 90 $\mathrm{mmHg}$ for diastolic [17]. EDS was evaluated by the Epworth scale [17]. EDS was defined by an Epworth score $\geq 10$ [24]. Ethical clearance was obtained from the Institutional Review Board of the Faculty of Medicine and Pharmaceutical Sciences of the University of Douala.

\subsection{Data Analysis}

Our data were analyzed using IBM-SPSS 20 for Windows (IBM, Chicago, USA). Qualitative data were summarized in terms of counts and frequencies. Quantitative variables were described by their mean (standard deviation) or median $\left(25^{\text {th }}\right.$ $75^{\text {th }}$ percentiles) according to the type of distribution of variables. The Chi-2 test was used for the comparison of proportions while quantitative variables were compared using the non-parametric Mann-Whitney $U$ test. Logistic regression analysis was used to identify the factors associated to EDS. The factors associated with EDS in univariate analysis with $\mathrm{p}<0.10$ were introduced 
into the same multinomial logistic regression model to search for independent factors associated to EDS. At this level a difference was considered significant if $\mathrm{p}<0.05$.

\section{Results}

\subsection{General Characteristics of the Study Population}

Of the 8415 subjects interviewed, 127 subjects had no information on EDS or hypertension and were excluded from the analysis. Of the 8288 subjects definitively included, 3031 (36.6\%), 2669 (32.2\%), 1638 (19.8\%) and 950 (11.5\%) were respectively recruited in Bandjoun, Douala, Garoua and Figuil. There were 4579 (55.2\%) women and 3709 (44.8\%) men with the median $\left(25^{\text {th }}-75^{\text {th }}\right.$ percentiles $)$ age of $39(27-54)$ years. Obesity and overweight were found in $29.5 \%$ and $22 \%$ of subjects, respectively. The prevalence of hypertension in this study was $28.5 \%$ (95\% CI: 27.6-29.5\%) and that of EDS was $12.1 \%$ (95\% CI: $11.4 \%-12.8 \%$ ). The general characteristics of the study population are presented in Table 1.

Table 1. General characteristics of study population.

\begin{tabular}{|c|c|}
\hline Characteristics & $\mathrm{N}=8288(\%)$ \\
\hline \multicolumn{2}{|l|}{ Residency } \\
\hline Bandjoun & $3031(36.6)$ \\
\hline Douala & $2669(32.2)$ \\
\hline Garoua & $1638(19.8)$ \\
\hline Figuil & $950(11.5)$ \\
\hline \multicolumn{2}{|l|}{ Gender } \\
\hline Men & $3709(44.8)$ \\
\hline Women & $4579(55.2)$ \\
\hline Age, years, median $\left(25^{\text {th }}-75^{\text {th }}\right.$ percentiles $)$ & $39(27-54)$ \\
\hline \multicolumn{2}{|l|}{ Education } \\
\hline$\leq$ Primary & $3758 / 8287(45.3 \%)$ \\
\hline Secondary & $3099 / 8287(37.4)$ \\
\hline University & $1430 / 8287(17.3)$ \\
\hline \multicolumn{2}{|l|}{ Marital status } \\
\hline Living in couple & $4603 / 8274(55.5)$ \\
\hline Living alone & $3671 / 8274(44.3)$ \\
\hline \multicolumn{2}{|l|}{ Ethnicity } \\
\hline Semi-bantu & $4504 / 8277(54.4)$ \\
\hline Sudanese & $1674 / 8277(20.2)$ \\
\hline Bantu & $1278 / 8277(15.4)$ \\
\hline Fulani & $504 / 8277(6.1)$ \\
\hline Other & $317 / 8277(3.8)$ \\
\hline \multicolumn{2}{|l|}{ Tobacco use } \\
\hline Smokers & $579 / 8280(7)$ \\
\hline Ex-smokers & $521 / 8280(6.3)$ \\
\hline Non-smokers & $7180(86.6)$ \\
\hline \multicolumn{2}{|l|}{ Alcohol use } \\
\hline Occasional & $3829 / 5696(67.2)$ \\
\hline Regular & $809 / 5696(14.2)$ \\
\hline Former & $322 / 5696(5.7)$ \\
\hline No Consumption & $736 / 5696(12.9)$ \\
\hline BMI, $\mathrm{kg} / \mathrm{m}^{2}$, median $\left(25^{\text {th }}-75^{\text {th }}\right.$ percentiles $)$ & $25.2(22.1-29.3)$ \\
\hline \multicolumn{2}{|l|}{ BMI categories } \\
\hline Normal & $3632 / 8247(44)$ \\
\hline Underweight & $366 / 8247(4.4)$ \\
\hline Overweight & $2436 / 8247(29.5)$ \\
\hline Obesity & $1813 / 8247(22)$ \\
\hline Hypertension & $2365(28.5)$ \\
\hline Excessive daytime sleepiness & $1000(12.1)$ \\
\hline
\end{tabular}

BMI, body mass index.

\subsection{Association Between Excessive Daytime Sleepiness and Hypertension}

In univariate analysis, the prevalence of EDS was higher in subjects who had hypertension than in those who did not, with a significant difference $(13.4 \%$ vs $11.5 \%, p=0.015)$ with an odds ratio $(95 \% \mathrm{CI})$ of 1.19 (1.04-1.37). The mean Epworth score (SD) was 4.4 (4.2) in the hypertension group and $4.0(4.1)$ in the group without hypertension $(\mathrm{p}<0.001)$.

The results of the multivariate analysis of the association between EDS and hypertension, and potential confounding factors (sex, age, place of residence, education level, ethnic group, BMI) are presented in Table 2. After adjusting for potential confounding factors, EDS was no longer associated with hypertension [adjusted odds ratio $(95 \% \mathrm{CI})$ : $1.01(0.86-$ $1.18), \mathrm{p}=0.944]$.

Table 2. Multivariate analysis of associated factors to excessive daytime sleepiness.

\begin{tabular}{lll}
\hline Factors & OR (IC à 95\%) & p \\
\hline Men & $1.25(1.08-1.44)$ & 0.003 \\
Age & $1.00(0.99-1.01)$ & 0.934 \\
Residency & & \\
Figuil & 1 & \\
Bandjoun & $3.42(2.27-5.15)$ & $<0.001$ \\
Douala & $4.23(2.83-6.34)$ & $<0.001$ \\
Garoua & $1.27(0.90-1.79)$ & 0.168 \\
Education & $1.36(0.86-2.14)$ & 0.192 \\
University & 1 & \\
Secondary & $1.57(1.28-1.93)$ & $<0.001$ \\
$\leq$ Primary & $1.49(1.17-1.91)$ & 0.001 \\
Ethnicity & & \\
Fulani & 1 & \\
Semi-bantu & $0.86(0.54-1.38)$ & 0.535 \\
Bantu & $0.95(0.58-1.56)$ & 0.844 \\
Sudanese & $1.71(1.13-2.58)$ & 0.011 \\
Others & $0.81(0.45-1.45)$ & 0.476 \\
BMI, per1 kg/m ${ }^{2}$ increase & $1.04(1.03-1.06)$ & $<0.001$ \\
Hypertension & $1.01(0.86-1.18)$ & 0.944 \\
\hline
\end{tabular}

OR, odds ratio; BMI, body mass index.

\subsection{Determinants of Excessive Daytime Sleepiness in Subjects with Hypertension}

The determinants of EDS in subjects with hypertension are presented in Table 3 (univariate analysis) and Table 4 (multivariate analysis). In the univariate analysis, sex, age, smoking and alcohol use were not associated with EDS in hypertensive subjects. On the other hand, place of recruitment, education level, marital status, ethnic group and BMI were associated with EDS in hypertensive subjects.

Table 3. Univariate analysis of factors associated to excessive daytime sleepiness (EDS) in patients with hypertension.

\begin{tabular}{llll}
\hline Factors & EDS N = 318 (\%) & No EDS 2047 (\%) & p \\
\hline Gender & & & \\
Men & $148(46.5)$ & $944(46.1)$ & 0.888 \\
Women & $170(53.5)$ & $1103(53.9)$ & \\
Age, years, mean (SD) & $50.9(16.3)$ & $51.2(17.2)$ & 0.821 \\
Residency & & & \\
Bandjoun & $137(43.1)$ & $873(42.6)$ & $<0.001$ \\
Douala & $128(40.3)$ & $589(28.8)$ & \\
\hline
\end{tabular}




\begin{tabular}{|c|c|c|c|}
\hline Factors & EDS N $=318(\%)$ & No EDS 2047 (\%) & $\mathbf{p}$ \\
\hline Garoua & $40(12.6)$ & 347 (17) & \\
\hline Figuil & $13(4.1)$ & $238(11.6)$ & \\
\hline \multicolumn{4}{|l|}{ Education } \\
\hline$\leq$ primairy & $155(48.7)$ & $1116(54.5)$ & 0.060 \\
\hline Secondary & $124(39)$ & $661(32.3)$ & \\
\hline University & $39(12.3)$ & $270(13.2)$ & \\
\hline \multicolumn{4}{|l|}{ Marital status } \\
\hline Living in couple & $198 / 318(62.3)$ & $1162 / 2045(56.8)$ & 0.068 \\
\hline No in couple & $120 / 318(37.7)$ & $883 / 2045(43.2)$ & \\
\hline \multicolumn{4}{|l|}{ Ethnic group } \\
\hline Semi-bantu & $194 / 318(61)$ & $1161 / 2045(56.8)$ & 0.076 \\
\hline Sudanese & $45 / 318(14.2)$ & $359 / 2045(17.6)$ & \\
\hline Bantu & $59 / 318(18.6)$ & $330 / 2045(16.1)$ & \\
\hline Fulani & $7 / 318(2.2)$ & $102 / 2045(5)$ & \\
\hline Others & $13 / 318(4.1)$ & $92 / 2045(4.5)$ & \\
\hline \multicolumn{4}{|l|}{ Smoking habits } \\
\hline Smokers & $23 / 316(7.3)$ & $137 / 2047(6.7)$ & 0.668 \\
\hline Former smokers & $27 / 316(8.5)$ & 206/2047 (10.1) & \\
\hline Non-smokers & $266 / 316(84.2)$ & $1704 / 2047(83.2)$ & \\
\hline \multicolumn{4}{|l|}{ Alcohol consumption } \\
\hline Occasional & $178 / 264(67.4)$ & $961 / 1462(65.7)$ & 0.104 \\
\hline Regular & $45 / 264(17)$ & $205 / 1462(14)$ & \\
\hline Former & $13 / 264(4.9)$ & $133 / 1462(9.1)$ & \\
\hline No & $28(10.6)$ & $163 / 1462(84.7)$ & \\
\hline $\begin{array}{l}\mathrm{BMI}, \mathrm{Kg} / \mathrm{m}^{2} \text {, mean } \\
\text { (SD) }\end{array}$ & $29.9(6.4)$ & $27.9(6.4)$ & $<0.001$ \\
\hline \multicolumn{4}{|l|}{ BMI categories } \\
\hline Normal & $74 / 315(23.5)$ & $672 / 2037$ (33) & $<0.001$ \\
\hline Underweight & $5 / 315(1.6)$ & $81 / 2037$ (4) & \\
\hline Overweight & 90/315 (28.6) & $624 / 2037(30.6)$ & \\
\hline Obese & $146 / 315(46.3)$ & $660 / 2037(32.4)$ & \\
\hline
\end{tabular}

SD, standard deviation; BMI, body mass index.

In the multivariate analysis, the determinants of EDS in subjects with hypertension were residence in Douala [adjusted odds ratio $(95 \% \mathrm{CI}): 5.57$ (2.52-12.33)], residence in Bandjoun $[3.98(1.80-8.80), \mathrm{p}<0.001]$, being a Sudanese [2.51 (1.02-6.15), p = 0.044] and obesity [1.63 (1.18-2.23), $\mathrm{p}$ $=0.003]$.

Table 4. Multivariate analysis of factors associated to excessive daytime sleepiness (EDS) in patients with hypertension.

\begin{tabular}{lll}
\hline Factors & OR $($ IC à 95\%) & p \\
\hline Residency & & \\
Figuil & 1 & \\
Bandjoun & $3.98(1.80-8.80)$ & 0.001 \\
Douala & $5.57(2.52-12.33)$ & $<0.001$ \\
Garoua & $1.89(0.97-3.68)$ & 0.063 \\
Education level & & \\
University & 1 & \\
Secondary & $1.16(0.78-1.73)$ & 0.472 \\
S primary & $1.12(0.75-1.65)$ & 0.294 \\
Ethnicity & & \\
Fulani & 1 & \\
Semi-bantu & $1.21(0.43-3.35)$ & 0.720 \\
Sudanese & $2.51(1.02-6.15)$ & 0.044 \\
Bantu & $0.98(0.34-2.81)$ & 0.972 \\
Others & $1.38(0.45-4.24)$ & 0.578 \\
BMI categories & & \\
Normal & 1 & \\
Underweight & $0.75(0.29-1.93)$ & 0.546 \\
Overweight & $1.17(0.83-1.63)$ & 0.373 \\
Obese & $1.63(1.18-2.23)$ & 0.003 \\
\hline
\end{tabular}

\section{Discussion}

In this study, conducted in a sub-Saharan African country and including more than 8,000 community-recruited subjects, we found that: 1) the prevalence of EDS was higher in subjects with hypertension 2) there was no independent association between EDS and hypertension 3) the determinants of EDS in subjects with hypertension were residence in Douala or Bandjoun, belonging to the Sudanese ethnic group and obesity.

In this study, we found that in univariate analysis, the prevalence of EDS was higher in subjects with hypertension compared to those without hypertension but this association disappeared in multivariate analysis after taking into account the socio-demographic and anthropometric confounding factors. In the study by Goldstein et al. published in 2004 and covering a cohort of 133 adult subjects followed for 5 years, EDS was a risk factor for the occurrence of hypertension [18]. Studies in subjects with SAS indicate that there is an independent association between EDS and hypertension [13, 16, 18]. For example, in a large study of 1958 patients seen in a Western China Sleep Disorders Center, Epworth-based EDS was independently associated with hypertension with an adjusted odds ratio of 1.23 in apneic subjects [14]. Using objective measures of daytime sleepiness such as the iterative sleep latency test, Ren et al. found that a sleep latency $<5$ minutes and between 5 and 8 minutes increased the odds of hypertension by $95 \%$ and $111 \%$ respectively [16]. However, in a comparative study involving 304 hypertensive subjects and 67 normotensive subjects, the mean Epworth score was significantly lower in hypertensive subjects [15].

In hypertensive patients with or without SAS, the prevalence of EDS appears to be high. Thus, in a study carried out in a tertiary hospital in Cameroon, the prevalence of subjective EDS evaluated by the Epworth scale was $62.8 \%$ in adult subjects with hypertension [21]. In our study, the prevalence of EDS was $13.4 \%$ in hypertensive patients, significantly lower than that reported by Mbatchou et al. [21]. This difference can be explained by the fact that the subjects included in the latter study were recruited in hospitals contrary to the subjects included in our study. Thus, it is possible that some co-morbid conditions associated with EDS are more frequent among hospital-recruited subjects.

In our study, place of residence, Sudanese ethnicity and obesity were associated with EDS in hypertensive subjects. In the series of Stater et al. including 173 apneic and nonapneic patients recruited from a London sleep study center, obesity was associated with EDS regardless of other sleep disorders and hypertension [25]. After adjusting for confounding factors, our obese subjects were $63 \%$ more likely to have EDS compared to subjects with normal BMI. This risk was $175 \%$ in the study including 411 hypertensive subjects recruited from a hospital center in Douala, Cameroon [21]. Other studies have also reported an association between obesity and $\operatorname{EDS}[9,26]$.

The Sudanese ethnic group was independently associated with EDS in hypertensive subjects in our study. The subjects 
belonging to this ethnic group were mainly recruited in the areas of northern Cameroon (62\% in Garoua and 34\% in Figuil), areas in which the prevalence of EDS was significantly lower. Thus, specific studies should be conducted in this ethnic group to determine the reasons for this association; for example, the more frequent occurrence of conditions associated with EDS such as sleep apnea syndrome, sleep insufficiency, chronic insomnia and other sleep disorders. The independent association between the EDS and the Bandjoun and Douala residences, located respectively in the West and Littoral regions of Cameroon could be explained by the socio-environmental factors (type of occupation, social interactions) and even the psychological profile of the subjects. Indeed, Goldstein et al. suggest that the Epworth scale outside the measure of the propensity to doze in particular situations, could also include the measurement of psychological factors [18].

We found no association between gender, age, marital status, level of education, smoking and alcohol consumption. These results corroborate those found in other studies [18, 21, 27]. In a study conducted in the Canadian rural general population and including 7597 subjects, EDS was associated with age, male sex, low socio-economic status and married subjects [26].

The main limitations of this study are the use of a subjective measurement method for the evaluation of the EDS (Epworth Scale) and its cross-sectional nature which does not allow us to have chronologic link between EDS and the potential risk factors. Nevertheless, the Epworth scale is widely used in epidemiological and clinical studies for the evaluation of EDS, allowing a comparison between the results of different studies [24]. In addition, the psychometric validity of the Epworth score has recently been reported in the African population [28].

\section{Conclusion}

In this large population-based study in a sub-Saharan African country, we found no independent association between excessive daytime sleepiness and hypertension. In hypertensive subjects, Sudanese ethnicity, residence in Bandjoun or Douala and obesity are factors independently associated with EDS. Thus, EDS should be systematically evaluated for in hypertensive and obese subjects in order to identify the cause as this will permit optimal management of these patients. In addition, other studies should examine the reasons for a higher prevalence of EDS in Sudanese hypertensive patients and also in those living in West and Littoral region of Cameroon. The reduction of body mass index should also allow a reduction of burden of EDS in hypertensive subjects.

\section{References}

[1] Sagaspe P, Taillard J, Bayon V, Lagarde E, Moore N, Boussuge $J$, et al. Sleepiness, near-misses and driving accidents among a representative population of French drivers. J Sleep Res. 2010; 19: 578-84. doi: 10.1111/j.13652869.2009.00818.x.
[2] Garbarino S, Guglielmi O, Sanna A, Mancardi GL, Magnavita N. Risk of Occupational Accidents in Workers with Obstructive Sleep Apnea: Systematic Review and Meta-analysis. Sleep. 2016; 39: 1211-8. doi: 10.5665/sleep.5834.

[3] Thorpy MJ. Classification of sleep disorders. Neurotherapeutics. 2012 ;9: 687-701. doi: 10.1007/s13311012-0145-6.

[4] Theorell-Haglöw J, Lindberg E, Janson C. What are the important risk factors for daytime sleepiness and fatigue in women? Sleep. 2006; 29: 751-7. doi: 10.1093/sleep/29.6.751.

[5] Ohayon MM, Caulet M, Philip P, Guilleminault C, Priest RG. How sleep and mental disorders are related to complaints of daytime sleepiness. Arch Intern Med. 157: 2645-52.

[6] Liu X, Uchiyama M, Kim K, Okawa M, Shibui K, Kudo Y, et al. Sleep loss and daytime sleepiness in the general adult population of Japan. Psychiatry Res. 2000; 93: 1-11. doi: 10.1016/s0165-1781 (99) 00119-5.

[7] Joo S, Baik I, Yi H, Jung K, Kim J, Shin C. Prevalence of excessive daytime sleepiness and associated factors in the adult population of Korea. Sleep Med. 2009; 10: 182-8. doi: 10.1016/j.sleep.2008.03.017.

[8] Nugent AM, Gleadhill I, McCrum E, Patterson CC, Evans A, MacMahon J. Sleep complaints and risk factors for excessive daytime sleepiness in adult males in Northern Ireland. J Sleep Res. 2001; 10: 69-74. http://www.ncbi.nlm.nih.gov/pubmed/11285057.

[9] Vashum KP, McEvoy MA, Hancock SJ, Islam MR, Peel R, Attia JR, et al. Prevalence of and associations with excessive daytime sleepiness in an Australian older population. AsiaPacific J public Heal. 2015; 27: NP2275-84. doi: 10.1177/1010539513497783.

[10] Hara C, Lopes Rocha F, Lima-Costa MFF. Prevalence of excessive daytime sleepiness and associated factors in a Brazilian community: the Bambuí study. Sleep Med. 2004; 5: 31-6. http://www.ncbi.nlm.nih.gov/pubmed/14725824.

[11] Johns M, Hocking B. Daytime sleepiness and sleep habits of Australian workers. Sleep. 1997; 20: 844-9. doi: $10.1093 /$ sleep/20.10.844.

[12] Ng TP, Tan WC. Prevalence and determinants of excessive daytime sleepiness in an Asian multi-ethnic population. Sleep Med. 2005; 6: 523-9. doi: 10.1016/j.sleep.2005.01.007.

[13] Wang Q, Zhang C, Jia P, Zhang J, Feng L, Wei S, et al. The association between the phenotype of excessive daytime sleepiness and blood pressure in patients with obstructive sleep apnea-hypopnea syndrome. Int J Med Sci. 2014; 11: 713-20. doi: 10.7150/ijms.7487.

[14] Du LN, Ren R, Tan L, Li TM, Lei F, Tang XD, et al. [Association between daytime sleepiness and hypertension among patients with obstructive sleep apnea-hypopnea syndrome]. Zhonghua Yi Xue Za Zhi. 2016; 96: 3370-4. doi: 10.3760/cma.j.issn.0376-2491.2016.42.003.

[15] Martynowicz H, Skomro R, Gać P, Mazur G, Porębska I, Bryłka A, et al. The influence of hypertension on daytime sleepiness in obstructive sleep apnea. J Am Soc Hypertens. 2017; 11: 295-302. doi: 10.1016/j.jash.2017.03.004. 
[16] Ren R, Li Y, Zhang J, Zhou J, Sun Y, Tan L, et al. Obstructive Sleep Apnea With Objective Daytime Sleepiness Is Associated With Hypertension. Hypertens (Dallas, Tex 1979). 2016; 68: 1264-70. doi: 10.1161/HYPERTENSIONAHA.115.06941.

[17] Chobanian A V., Bakris GL, Black HR, Cushman WC, Green LA, Izzo JL, et al. Seventh Report of the Joint National Committee on Prevention, Detection, Evaluation, and Treatment of High Blood Pressure. Hypertension. 2003; 42: 1206-52. doi: 10.1161/01.HYP.0000107251.49515.c2.

[18] Goldstein IB, Ancoli-Israel S, Shapiro D. Relationship between daytime sleepiness and blood pressure in healthy older adults. Am J Hypertens. 2004; 17: 787-92. doi: 10.1016/j.amjhyper.2004.05.009.

[19] Drager LF, Santos RB, Silva WA, Parise BK, Giatti S, Aielo AN, et al. OSA, Short Sleep Duration, and Their Interactions With Sleepiness and Cardiometabolic Risk Factors in Adults: The ELSA-Brasil Study. Chest. 2019; 155: 1190-8. doi: 10.1016/j.chest.2018.12.003.

[20] Tam W, Ng SS, To K-W, Ko FW, Hui DS. The interaction between hypertension and obstructive sleep apnea on subjective daytime sleepiness. J Clin Hypertens (Greenwich). 2019; 21: 390-6. doi: 10.1111/jch.13485.

[21] Mbatchou Ngahane BH, Nganda MM, Dzudie A, Luma H, Kamdem F, Ngote HR, et al. Prevalence and determinants of excessive daytime sleepiness in hypertensive patients: a crosssectional study in Douala, Cameroon. BMJ Open. 2015; 5: e008339. doi: 10.1136/bmjopen-2015-008339.

[22] Pefura-Yone EW, Kengne AP, Balkissou AD, Boulleys-Nana JR, Efe-de-Melingui NR, Ndjeutcheu-Moualeu PI, et al.
Prevalence of Asthma and Allergic Rhinitis among Adults in Yaounde, Cameroon. PLoS One. 2015; 10: e0123099. doi: 10.1371/journal.pone.0123099.

[23] Lydia Gisle SD. Enquête de santé 2013. rapport 2: comportement de santé et style de vie. https://his.wivisp.be/fr/Documents partages/AL_FR_2013.pdf.

[24] Johns MW. Reliability and factor analysis of the Epworth Sleepiness Scale. Sleep. 1992; 15: 376-81. doi: 10.1093/sleep/15.4.376.

[25] Slater G, Pengo MF, Kosky C, Steier J. Obesity as an independent predictor of subjective excessive daytime sleepiness. Respir Med. 2013; 107: 305-9. doi: 10.1016/j.rmed.2012.10.013.

[26] Gjevre JA, Pahwa P, Karunanayake C, Hagel L, Rennie D, Lawson $\mathrm{J}$, et al. Excessive daytime sleepiness among rural residents in Saskatchewan. Can Respir J. 21: 227-33. doi: $10.1155 / 2014 / 921541$.

[27] Whitney CW, Enright PL, Newman AB, Bonekat W, Foley D, Quan SF. Correlates of daytime sleepiness in 4578 elderly persons: the Cardiovascular Health Study. Sleep. 1998; 21: 27-36. doi: 10.1093/sleep/21.1.27.

[28] Manzar MD, Salahuddin M, Alamri M, Albougami A, Khan MYA, Nureye D, et al. Psychometric properties of the Epworth sleepiness scale in Ethiopian university students. Health Qual Life Outcomes. 2019; 17: 30. doi: 10.1186/s12955-019-1098-9. 